\title{
How Generation Z College Students Prefer to Learn: A Comparison of U.S. and Brazil Students
}

\author{
Corey Seemiller \\ Wright State University \\ Meghan Grace \\ Vanderbilt University \\ Paula Dal Bo Campagnolo \\ Unisinos University \\ Isa Mara Da Rosa Alves \\ Unisinos University \\ Gustavo Severo De Borba \\ Unisinos University
}

\begin{abstract}
The purpose of this study was to engage in a comparative analysis of Generation $\mathrm{Z}$ college students in the United States and Brazil regarding characteristics, motivations, interpersonal styles, learning styles, and learning methods. Quantitative data in both countries were collected and analyzed to formulate comparative findings. Themes that emerged include learning that makes a difference, achievement orientation, logic-based learning, intrapersonal and interpersonal learning, applied and hands-on experiences, learning through words, recognition, and lacking vision, inspiration, and creativity. More similarities than differences were found across themes in both populations.
\end{abstract}

Keywords: Generation Z, learning styles, motivation, international comparative learning, higher education

\section{Introduction}

Today's traditional-age college cohort is composed of those in Generation Z, born 1995 through 2010. This generation is uniquely situated in a time period different than their predecessor college student generational cohorts, most recently Millennials, and is likely attending college in which programs, courses, processes, and pedagogies were designed for those who came before them. Thus, understanding this generation can provide a roadmap for educators in designing learning environments that best leverage the potential of today's Generation Z college students.

But, is how Generation $\mathrm{Z}$ prefers to learn the same across cultural contexts? This article aims to not only shed light on Generation Z's learning preferences but also highlight the similarities and differences between Generation Z college students in both the United States and Brazil.

\section{Higher Education in the United States}

The United States has a population of 329 million and is the third largest country globally (World Population Review, 2019). There are more than 4,600 institutions of higher education in the United States (U.S. Department of Education, 2018), with great variation in institution type including 2- 
year, 4-year, vocational, nonprofit, for-profit, public, private, and religiously affiliated colleges and universities (Schloss \& Cragg, 2013). Today's college student population in the United States is composed of more than 18 million students (National Student Clearinghouse Research Center, 2017), many who are members of Generation Z.

Although the trend of college attendance had previously risen with each generation (Graf, 2016), total enrollment numbers in the United States have decreased by at least 1\% each semester since the fall of 2014 (National Student Clearinghouse Research Center, 2017). This decrease in total enrollment numbers aligns with the years in which the oldest of Generation $\mathrm{Z}$ began enrolling in college. While there may be several factors contributing to the decrease in college enrollment in the United States, it should also be recognized that Generation Z is smaller in terms of cohort population size in comparison to the Millennials who came before them (Knoema, 2018). With a smaller population size, the pool of traditional-aged prospective college students is more limited. Thus, meeting the learning needs of this generation could play a critical role in recruiting and retaining them as college students.

\section{Higher Education in Brazil}

Brazil ranks as the fifth largest country in the world with more than 212 million people (World Population Review, 2019). The higher education system in Brazil reflects this enormity and is composed of 2,448 private and public institutions (Brazil Ministry of Education, 2017). Although there is a great variation in institution type among these 2,448 institutions, only 199 are universities but enroll 53.7\% of all students (Brazil Ministry of Education, 2017). To be classified as a university in Brazil, the institution must offer a minimum of two doctoral programs and four master's degree programs. Catholic institutions also play an important role in the Brazilian educational system by promoting regional development from the local level and developing educational and research networks on a global scale (Brazil Ministry of Education, 2017).

In 2017, 3.2 million first-year students enrolled at institutions of higher education in Brazil, most at private institutions (Brazil Ministry of Education, 2017). The total number of students in Brazil as documented in 2017 was approximately 8.3 million, with $29 \%$ being in the Generation $\mathrm{Z}$ birth range and 54\% being in the Millennial birth range (Brazil Ministry of Education, 2017).

Both the United States and Brazil are G20 countries (i.e., the world's 20 largest economies) in a highly globalized world, and both have a significant number of young people attending college. Yet, the nuanced differences of language, cultural history, geography, and societal norms may impact how each group of students prefers to learn.

\section{Literature Review}

Learning in college does not take place haphazardly. There are several considerations for educators when determining how to most effectively facilitate learning. Understanding students' characteristics, sources of motivation, interpersonal styles, and preferences in learning styles and methods can be instructive in developing learning environments and experiences most conducive to student success.

\section{Characteristics}

With multiple entities aspiring to describe this generation, there is a growing body of research with emerging themes that begin to capture the characteristics of Generation Z. For example, the VIA Institute on Character (http://www.viacharacter.org/) employs a survey rooted in positive psychology that aids in understanding each individual's unique blend and application of 24 different character strengths. As of 2018, more than 7 million people had taken the VIA Survey of Character Strengths, 
including members of Generation Z in the United States and Brazil (VIA Institute on Character, 2018). The five character strengths associated with the highest number of Generation $Z$ respondents in the United States include honesty, kindness, humor, fairness, and judgment, and in Brazil include honesty, kindness, fairness, love, and judgment; only humor (United States) and love (Brazil) were different (VIA Institute on Character, 2018). In addition, both sets of respondents had the fewest people identify self-regulation as a strength (VIA Institute on Character, 2018).

Research, however, has been limited in providing comparative data on characteristics of members of Generation Z in both the United States and Brazil. U.S. data might offer insight into the characteristics of Generation Z specific to the United States. For instance, the Higher Education Research Institute in the United States found that $80 \%$ or more of the Generation $\mathrm{Z}$ college seniors reported having above-average abilities in seeing the world from someone else's perspective, practicing tolerance, and cooperating with others of diverse backgrounds (Higher Education Research Institute, 2017). Additionally, 80\% reported their drive to succeed to be above average compared to the average person their age (Higher Education Research Institute, 2017). Steele Flippin (2017) also aimed to characterize this generation through a multigenerational study, finding that U.S. Generation Z respondents described themselves as eager, hardworking, creative, and motivated.

\section{Interpersonal Styles}

The concept of interpersonal styles refers to how individuals interact with others. While there does not appear to be research that offers comparative data on interpersonal styles specifically about the United States and Brazil, understanding models and theories related to interpersonal styles can offer some guidance.

The Big Five personality trait model asserts that human personalities are divided into five primary categories: openness, conscientiousness, extraversion, agreeableness, and neuroticism (Cherry, 2018b). While the Big Five is not specifically a model of interpersonal styles, each individual's disposition falls on a spectrum of each personality category, which can create an element of differentiation between individuals and their predispositions (Cherry, 2018b). Thus, the Big Five is an informative lens for assessing team performance (Kichuk \& Wiesner, 1997).

In a study of over 10,000 respondents spanning in age from 20 to 96 years old, Costa et al. (1986) found that Big Five personality traits are influenced by demographic factors. For example, respondents scored higher in the traits of extraversion, neuroticism, and openness to experience when they were younger than when they were retested in the follow-up portion of the study (Costa et al., 1986). In a comparative study of the Big Five personality characteristics across 56 countries, data from U.S. and Brazil college students point to slight differences in means for each characteristic (Schmitt, Allik, McCrae, \& Benet-Martinez, 2007). The U.S. sample had higher means for extraversion, agreeableness, and conscientiousness, whereas the Brazil sample was higher in neuroticism; both were similar in openness (Schmitt et al., 2007).

In looking more specifically at interpersonal styles, Belbin's (2000) research on team roles, or "a pattern of behavior that characterizes one person's behavior in relationship to another," can be informative (p. 11). Through a self-reported psychometric-type test, the Belbin Team Role SelfPerception Inventory measures behavioral characteristics that are influenced by many factors such as values, motivation, prior experiences, and internal influences (Belbin, 2014). The team roles model clusters behaviors into nine roles a person can play in social or group interactions. The nine roles are categorized as action (completer finisher, implementer, and shaper), social (coordinator, resource investigator, and teamworker), or thinking (monitor evaluator, plant, and specialist; Belbin, 2014). While research on undergraduate college students' preference for specific team roles is sparse, 
a study of U.S. Master of Business Administration students found that the most prominent roles include resource investigator and completer finisher (Rushmer, 1996). A study of managers in the United Kingdom, however, found that the most prominent roles include coordinators and resource investigators, with the least prominent being completer finishers, monitor evaluators, shapers, and plants (Fisher, Hunter, \& Macrosson, 2000). Despite the data from the United Kingdom being unrelated to either country in this study, the differentiation in findings between the United States and United Kingdom highlights the importance of considering context and culture in role preference. Little research is available on the use of Belbin roles by a study sample from Brazil.

\section{Motivation}

Motivation is "the force that initiates, guides, and maintains goal-oriented behaviors" (Cherry, 2018a, para. 2). Self-determination theory postulates that motivation takes shape from either intrinsic or extrinsic sources and that motivation is facilitated by social and environmental factors (Ryan \& Deci, 2000). Intrinsic motivation is characterized by an internal drive, such as inherent interest or enjoyment, whereas extrinsic motivation leads to action or interest due to an external outcome, such as a tangible reward or avoiding a punishment (Deci \& Ryan, 2000).

Lumsden (1994) conceptualized student motivation as "a student's desire to participate in the learning process" (p. 2), which aligns more with intrinsic forms of motivation and is associated with the meaningfulness or value a learner places on a learning activity. Bye, Pushkar, and Conway (2007) found that traditional-aged students reported lower levels of intrinsic motivation regarding learning compared to nontraditional students. While intrinsic motivation has been found to be more effective in learning, extrinsic motivation can also be effective (Ross, Perkins, \& Bodey, 2016). For example, a study by Lin and McKeachie (1999) found that college students whose levels of extrinsic motivation were moderate, versus high or low, had higher academic performance.

Achievement motivation refers to the expectation that "performance will be evaluated in relation to some standard of excellence" (International Encyclopedia of the Social Sciences, 2019, para. 1). McClelland (2005) argued that some situations and contexts can influence achievement motivation. These situations should provide some level of autonomy for people to find success on their own, engage in tasks with varying levels of difficulty and risk, and receive clear feedback on efforts (McClelland, 2005). Achieving goals or tasks may lead to internal satisfaction and serve as a form of intrinsic motivation. A study of U.S. students enrolled in an online course found a positive impact on student self-determination and motivation when students received support in the form of autonomy and enhancing competency (Chen \& Jang, 2010).

Motivation, however, is a culturally constructed phenomenon. For example, in North America and other Western countries, motivation is often intrinsic and comes from wanting or needing "to belong, to enhance self-esteem, to achieve, and to maintain cognitive consistency" (Markus, 2016, p. 162). In non-Western countries, however, motivation is based more on relationships in which cultural norms such as "fulfilling role-related duties and obligations, and maintaining face, honor, and status," set the standards of behavior (Markus, 2016, p. 162).

\section{Learning Methods}

While a learning style refers to how learners take in and process information, learning methods are the skills and actions learners engage in to participate in learning. Gardner's (1993) concept of multiple intelligences proposed that there is more than one way to effectively engage in information processing to understand concepts. Gardner suggested learning can take place through the use of eight different intelligences: linguistic, logical-mathematical, spatial, bodily-kinetic, musical, interpersonal, intrapersonal, and naturalist. The multiple-intelligences framework does not position 
learning from a style perspective but instead as the process of using different intellectual abilities for learning (Terada, 2018).

A study examining multiple intelligences among U.S. community college students found that more than $81 \%$ scored in the high range for intrapersonal, far higher than any other intelligence (Gutierrez, Perri, \& Quackenbush, 2006). Kinesthetic followed with just around 49\% and logical with $40 \%$ (Gutierrez et al., 2006). The lowest percentage scores in the high category included verbal/linguistic at around $21 \%$ and naturalist at nearly 26\% (Gutierrez et al., 2006). There is little research on multiple intelligences in a Brazilian context.

\section{Learning Styles}

The concept of learning styles focuses on "how learners gather, sift through, interpret, organize, come to conclusions, and 'store' information for further use" (Chick, 2018, para. 1). Kolb's experiential learning model (Kolb \& Kolb, 2005a) situates a learner's preference along a two-way continuum with the vertical axis focusing on perception, or how one goes about thinking about things (i.e. feeling vs. thinking), and the horizontal axis focusing on processing, or how one goes about doing things (i.e. doing vs. watching; Kolb \& Kolb, 2005a). Where one gravitates on each axis creates a plot that aligns with one of the four learning styles-diverging (which blends concrete experience and reflective observation), assimilating (which blends abstract conceptualization and reflective observation), converging (which blends abstract conceptualization and active experimentation), or accommodating (which blends concrete experience and active experimentation; Kolb \& Kolb, 2005a).

In exploring the reliability and internal validity of Kolb's Learning Styles Inventory, a study of undergraduate college students yielded results within the normal distribution range, furthering the support of the consistency and reliability of the instrument to measure and understand student learning styles (Kayes, 2005). But, Jaju, Hyokjin, and Zinkhan (2002) found that U.S. business students prefer both reflective observation as well as concrete experience, aligning with the diverging style, whereas Healey, Kneale, and Bradbeer (2005) found that U.S. geography students prefer assimilating, followed by diverging, converging, and then accommodating. A study of undergraduate students across higher education institutions in Brazil found that their highest preference was for assimilating, with diverging as the least preferred (Cerqueira, 2008). However, it is important to note that differences were found between several variables, including academic discipline (Cerqueira, 2008), making a generalized profile of students from each country difficult.

Despite the expansive literature available regarding learning methods and styles, though, some caution the use due to little empirical evidence presented and cited (Learning and Skills Research Centre, 2004; An \& Carr, 2017). For example, critiques of Gardner's work center on the notion that intelligences are really just cognitive styles and that they are too similar to IQ (Klein, 1997). There is also a similarity between the intelligences. Because some intelligences overlap in concept and semantics, it is hard to point to the distinction of each intelligence as a separate entity (Klein, 1997). In addition, some argue that intelligences are tied to skills, creating a "circular" effect where it is unknown whether the skill leads to the intelligence or the intelligence leads to the skill (p. 378). And, there is little evidence that an intelligence is related to achievement (Klein, 1997). In addition, An and Carr (2017) pointed out that with learning styles, there is a lack of a framework and no clear causal rationale for why a person might be one style or another as well as that constructs can better be explained in other theories. In addition, they argued that learning styles do not serve as an accurate indicator of one's skills or as a predictor of one's future achievement (An \& Carr, 2017).

Klein's (1997) critique of multiple intelligences and An and Carr's (2017) critique of learning styles are focused on a K-12 environment where students lack choice about their learning experiences, environments, and teachers, unlike college students who often have far more flexibility to select 
courses, majors, and professors based on their preferences. Thus, in a collegiate setting, students may opt not to take classes, unless required, that do not align with their learning preferences. For example, college students who choose face-to-face courses over online courses cite that they prefer the interpersonal interaction rather than the self-learning they would do in a virtual setting (Jaggars, 2014).

\section{Purpose of the Study and Method}

This study aimed to provide insights to advance the science of learning so as to effect programmatic, curricular, and pedagogical change that positively supports the Generation Z student population in their learning endeavors. By better understanding the perspectives, preferences, and behaviors of this generational cohort, educators can become informed of practices they can use to enhance student learning.

In addition, in analyzing data from two different countries, the authors would be able to better understand more so the similarities between their student groups, paving the way for opportunities to share and collaborate on curriculum and pedagogical approaches they design and use with Generation $\mathrm{Z}$ that may have a universal application with educators in both geographic regions.

\section{Research Question}

To better understand the perceptions, styles, and needs of Generation $\mathrm{Z}$ college students in both the United States and Brazil regarding learning, the following research question was asked:

What are the similarities and differences between Generation Z students in the United States and Brazil in their characteristics, motivations, interpersonal styles, and preferred learning methods and styles?

\section{Instrument Design}

The U.S. data for this article are from a research study conducted by the two U.S. authors of this article. These two authors designed the instrument in English, disseminated the survey in the United States, and collected and analyzed the data. The three other authors of this article from Brazil later conducted a study and included five quantitative measurements from the U.S. study, among other measurements specific to their research. The Brazil authors translated the selected measurements used on the U.S. survey to from English to Portuguese, first by engaging in the translation on their own and then by having the translated content verified and edited by a graduate student with a degree and proficiency in the English language. The Brazil survey was then piloted with two students and two professors, who were asked to explain what they believed each measurement was actually measuring. Once the researchers confirmed with the pilot group that each measurement was written as intended, the survey was launched and responses were collected. Because the measurements were quantitative, the scales between both the U.S. and Brazil surveys were the same and were comparable for analysis. Table 1 offers information about the instruments used in both studies. 
Table 1. Comparison of Survey Instruments

\begin{tabular}{|c|c|c|}
\hline Survey Information & $\begin{array}{l}\text { Generation Z Goes to College } \\
\text { Survey (United States) }\end{array}$ & $\begin{array}{c}\text { Generation Z in Brazil Survey } \\
\text { (Brazil) }\end{array}$ \\
\hline Purpose of the study & $\begin{array}{l}\text { To understand the } \\
\text { characteristics, styles, } \\
\text { motivations, preferences, } \\
\text { concerns, and outlook of } \\
\text { Generation Z college students }\end{array}$ & $\begin{array}{l}\text { To understand the characteristics, } \\
\text { perspectives, preferences, and } \\
\text { worries related to the motivation, } \\
\text { communication, social dynamics, } \\
\text { and learning processes of } \\
\text { Generation } Z \text { college students }\end{array}$ \\
\hline Methodology & Quantitative and qualitative & Quantitative and qualitative \\
\hline Total measurements & $\begin{array}{l}22 \text { Quantitative measurements } \\
6 \text { Qualitative measurements }\end{array}$ & $\begin{array}{l}8 \text { Quantitative measurements } \\
4 \text { Qualitative measurements }\end{array}$ \\
\hline $\begin{array}{l}\text { Measurements used in } \\
\text { this article }\end{array}$ & 5 Quantitative measurements & 5 Quantitative measurements \\
\hline Instrument type & Online survey on SurveyMonkey & Online survey on Google Forms \\
\hline
\end{tabular}

The research done in Brazil was conducted using the same five measurements as those used in the United States and include the following:

Characteristics: A 3-point scale measuring the extent to which 35 personality characteristics describe them.

Motivation factors: A 3-point scale measuring the extent to which 22 factors motivate them based on the Motivation Index (Seemiller, 2009).

Interpersonal styles. A 5-point scale measuring the frequency of their use of four interpersonal styles informed by Belbin's (2014) team roles. These include doing (executing tasks, getting things done, following direction), thinking (collecting, analyzing, and synthesizing information, planning, researching, asking "why?"), relating (connecting with, including, and developing others), and leading (taking charge/initiative, setting the tone for the group, influencing others).

Learning methods: A 3-point scale measuring the effectiveness of different types of learning methods; the descriptions of each method were included as-is, slightly adapted, or summarized from Bixler's (n.d.) compilation on multiple intelligences and based on Gardner's (1993) multiple intelligences:

Intrapersonal: Aware of strengths, weaknesses, and feelings, possesses independence and self-confidence, learns best by engaging in independent projects, enjoys pacing own instruction

Kinesthetic: Good at balance/coordination, enjoys learning through physical activities and hands-on learning experiences

Logical/Mathematical: Likes to explore patterns and relationships, likes experiments, asks questions, enjoys working with numbers, enjoys solving problems, classifies information, finds common basic principles

Musical: Sensitive to sound of environment, enjoys music or melody while studying or working, likes learning through rhythm

Linguistic: Enjoys reading and writing, word games, storytelling, learns from saying/hearing words, good memory for names/dates/places

Spatial: Works well with maps/charts/diagrams/visual aids, likes to design and create things, learns best by looking at pictures or watching videos

Interpersonal: "People person," likes talking to people, engages in social activities, learns best by relating, sharing, and participating in cooperative group environments 
Naturalist: In touch with nature, senses patterns, good at categorization, learns best by studying natural phenomenon in natural setting and learning about how things work (Bixler, n.d.)

The descriptions of learning methods (intelligences) were used solely to inform categories for the survey question and not as an individual assessment of preferred multiple intelligences. In this survey, participants were asked, "Please indicate to what extent each method of learning is effective for you." Participants were asked to rate, not rank, the effectiveness of each method, allowing them to identify many methods at the same level of effectiveness. Ranking, on the other hand, would have resulted in participants being associated with a particular dominant intelligence (the one they ranked the highest), and would thus reflect concerns expressed by scholars such as Klein (1997).

Learning styles: A 5-point scale measuring the frequency of their use of four different learning approaches, which were adapted from Kolb's experiential learning model (Kolb \& Kolb, 2005b) and given names more conducive for ease in understanding. The descriptions for each were included as is, slightly adapted, or summarized. These names and descriptions include

Logic: Prefers a concise and logical approach, requires clear explanation, likes to understand wide-ranging information and organize it in a clear logical format

Experience: "Hands-on" learning, relies on intuition, attracted to new challenges and experiences, prefers to take experimental approach

Practicality: Uses learning to find solutions to practical issues, prefers technical tasks, makes decisions by finding solutions to questions and problems

Imagination: Tends to watch to gather information, uses imagination to solve problems, prefers to look at things from different perspectives (Businessballs.com, n.d.)

While the categories for each style are based on Kolb's model, the model only serves a way to describe different approaches for student learning and not as a measure of being an exclusive learner of a particular style. In addition, the survey question, "How frequently do you use each of these styles/approaches when learning?" aims to be self-reflective and not evaluative. There is no ranking among choices, no use of an existing learning styles instrument, nor does the survey attempt to measure students' skill sets or predisposition of achievement, all of which have been critiques of learning styles (An \& Carr, 2007).

\section{Participant Recruitment}

The U.S. authors recruited participants for the Generation Z Goes to College Study in the United States through outreach to campus professionals requesting they send the survey link to their students. For this study, a "call for participating institutions notice" was shared on national listservs for higher education, social media groups for student affairs, as well as through direct emails and/or social media messages to professionals within the personal networks of the researchers. After securing campus professionals from participating institutions, the U.S. authors sent an email message and survey link for them to share directly with their students through email, social media, online discussion boards, and so on. In the Brazil study, the Brazil authors collected data in a similar manner by reaching out through professional networks. The survey link, however, was also shared directly from the researchers through social media. 


\section{Sample}

The sample for both studies differed regarding size and dates of data collection, as the U.S. study was conducted first and then later informed the Brazil study. However, the gender distribution and the number of participants were similar between both studies. Table 2 highlights information specific to the samples for each study, considering the research in the United States and Brazil.

Table 2. Comparison of Study Samples

\begin{tabular}{lcc}
\hline Study Information & $\begin{array}{c}\text { Generation Z Goes to } \\
\text { College Study }\end{array}$ & $\begin{array}{c}\text { Generation Z in Brazil } \\
\text { Study }\end{array}$ \\
\hline Participating institutions & 16 & 16 \\
Survey dates & September-October 2014 & April-May 2018 \\
Survey completion & 1,143 & 1,481 \\
Gender & $69 \%$ Women, $30.83 \%$ men, $<1 \%$ & $69.5 \%$ Women, $30.5 \%$ men \\
& transgender & 1,481 \\
Number of question responses & $701-760$ & \\
\hline
\end{tabular}

\section{Data Analysis}

The authors analyzed the findings of the survey data respective of their countries using percentage frequency as reported in the responses. Each measurement included in the surveys was ordinal, as each set of response choices was on an ordered 3- or 5-point scale. Measurements on a 3-point scale included the following choices: does not, somewhat, and greatly. Only those responses for greatly were included in the analysis. Measurements on a 5-point scale included never, rarely, sometimes, often, and always. Responses for often and always were consolidated into one total for analysis. Only descriptive statistics of frequency were used for this data analysis, and no inferential statistics were used.

In conducting a comparative analysis, the five authors compared findings from each measurement from the U.S. survey and Brazil survey. Because the U.S. data had been collected and analyzed before the start of data collection in Brazil, the U.S. authors were able to identify which five measurement constructs should be used in the Brazil instrument and then provided the parameters with which to conduct the analysis. For example, while the measurements were the same and used the same scales, the analysis needed to match as well. For example, only responses of often and always were included in the data reporting for measurements with a 5-point scale. Each measurement was its own variable, and because the goal of both studies was to understand Generation $\mathrm{Z}$ in the aggregate in each country, no dependent variables were considered in either analysis.

Once the data from the Brazil study had been collected and analyzed, the two U.S. researchers traveled to Brazil to compare the data first-hand. All five authors met for 2 days and wrote down their respective findings on a dry-erase board. One author served as a note-taker by entering the same information into a Google Doc. Once data from both studies were listed side by side, all five of the authors from both countries discussed the similarities and differences and derived emergent themes.

\section{Validity and Reliability}

Three different types of validity were considered in the design of the original U.S. survey, which was later translated and disseminated to the Brazil participants. First, in terms of face validity, both researchers discussed each instrument in an effort to agree on its ability to measure the construct. 
The wording was edited and clarified until both researchers agreed that each survey was designed to measure what was intended. In addition, measurements for interpersonal styles, learning styles, and learning methods included definitions of concepts for participants to better understand what was being measured.

To ensure content validity, measurements for motivations, interpersonal styles, learning styles, and learning methods were taken from existing theories and models, ensuring a more holistic and theoretically grounded assertion of the construct category. The only measurement that was not derived from existing literature was that of characteristics. Yet, the measurement does not presumptively assert that having high or low levels of any or all characteristics listed is associated with a particular personality type or predisposed category.

Construct validity is used when researchers "use a measure as an index of a variable that is not itself directly observable (e.g., intelligence, aggression, working memory)" (Westen \& Rosenthal, 2003 , p. 608). As this study does not purport to quantify a level of behavior using responses from the survey (e.g. intelligence level) but only to capture participants' self-perspectives of their styles and preferences, construct validity was not applicable.

In terms of reliability, internal consistency is considered when there are multiple items, or measurements, associated with one construct (Tang, Cui, \& Babenko, 2014). Because only one measurement was associated with each construct, internal consistency was not considered.

\section{Results}

The results of this study are presented by measurement as each reflects a particular concept related to Generation Z.

\section{Characteristics}

Participants in both studies were given a list of 35 personality characteristics and asked to indicate the extent to which each describes them. With three choices, does not, somewhat, and greatly, Table 3 outlines the frequency of responses for both studies of those who believe that the characteristic greatly describes them. 
Table 3. U.S. and Brazil Generation Z Student Characteristics

\begin{tabular}{lcc}
\hline Characteristic & U.S. Students $(\boldsymbol{n}=\mathbf{7 6 0})$ & Brazil Students $(\boldsymbol{n}=\mathbf{1 , 4 8 1})$ \\
\hline Adaptable & $55.4 \%$ & $49.1 \%$ \\
Adventurous & $52.9 \%$ & $42.6 \%$ \\
Analytical & $45.5 \%$ & $38.3 \%$ \\
Authentic & $60.3 \%$ & $50.6 \%$ \\
Cautious & $36.8 \%$ & $42.8 \%$ \\
Collaborative & $38.3 \%$ & $58.0 \%$ \\
Communicative & $41.1 \%$ & $43.8 \%$ \\
Compassionate & $73.0 \%$ & $55.3 \%$ \\
Competitive & $45.9 \%$ & $38.2 \%$ \\
Confident & $44.0 \%$ & $41.0 \%$ \\
Conservative & $31.4 \%$ & $17.7 \%$ \\
Cooperative & $59.7 \%$ & $59.5 \%$ \\
Courageous & $42.2 \%$ & $39.1 \%$ \\
Creative & $49.7 \%$ & $45.7 \%$ \\
Determined & $73.9 \%$ & $67.1 \%$ \\
Driven & $66.8 \%$ & $53.1 \%$ \\
Focused & $55.6 \%$ & $49.0 \%$ \\
Inclusive & $36.2 \%$ & $64.0 \%$ \\
Inspiring & $31.5 \%$ & $27.3 \%$ \\
Intellectual & $62.8 \%$ & $38.6 \%$ \\
Loyal & $84.5 \%$ & $76.3 \%$ \\
Open-minded & $69.6 \%$ & $73.4 \%$ \\
Opportunistic & $46.80 \%$ & $20.8 \%$ \\
Optimistic & $49.4 \%$ & $35.0 \%$ \\
Organized & $43.7 \%$ & $44.2 \%$ \\
Practical & $53.9 \%$ & $54.2 \%$ \\
Realistic & $61.9 \%$ & $63.6 \%$ \\
Resilient & $39.3 \%$ & $48.5 \%$ \\
Responsible & $68.9 \%$ & $67.1 \%$ \\
Sensible & $60.4 \%$ & $54.5 \%$ \\
Spontaneous & $31.0 \%$ & $49.0 \%$ \\
Thoughtful & $79.5 \%$ & $32.0 \%$ \\
Unique & $61.5 \%$ & $49.1 \%$ \\
Visionary & $36.2 \%$ & $32.9 \%$ \\
\hline & & \\
& & \\
\hline
\end{tabular}

\section{Motivations}

Participants in both studies were also asked to consider 22 different factors related to motivation and the extent to which each was motivating for them. Using 3-point scaling (does not, somewhat, and greatly), Table 4 includes the frequency of responses for those who indicated that the factor greatly motivates them. 
Table 4. U.S. and Brazil Generation Z Student Motivations

\begin{tabular}{lcc}
\hline Motivation Factor & U.S. Students $(\boldsymbol{n}=\mathbf{7 2 4})$ & Brazil Students $(\boldsymbol{n}=\mathbf{1 , 4 8 1})$ \\
\hline Not wanting to let others down & $75.3 \%$ & $47.0 \%$ \\
Making a difference for someone & $74.7 \%$ & $72.7 \%$ \\
Advocating for something you believe in & $74.7 \%$ & $74.5 \%$ \\
Credit & $74.2 \%$ & $47.4 \%$ \\
Opportunity for advancement & $74.2 \%$ & $86.3 \%$ \\
Tangible rewards & $69.2 \%$ & $75.6 \%$ \\
Seeing fruits of labor & $68.0 \%$ & $89.4 \%$ \\
Care about project & $68.0 \%$ & $42.5 \%$ \\
Wanting to do well because you took it on & $66.5 \%$ & $88.7 \%$ \\
Learning something & $66.3 \%$ & $79.9 \%$ \\
Avoiding penalties & $65.5 \%$ & $32.1 \%$ \\
Competition with self & $59.3 \%$ & $46.0 \%$ \\
Experience & $54.5 \%$ & $74.1 \%$ \\
Leaving a legacy & $51.5 \%$ & $58.7 \%$ \\
Pleasing others & $51.0 \%$ & $35.2 \%$ \\
Credibility & $46.4 \%$ & $30.5 \%$ \\
Loyal to one's community & $42.5 \%$ & $34.5 \%$ \\
Individual recognition & $37.3 \%$ & $66.0 \%$ \\
Competition with others & $37.2 \%$ & $29.6 \%$ \\
Acceptance by others & $30.3 \%$ & $17.4 \%$ \\
Public recognition & $27.3 \%$ & $32.1 \%$ \\
Someone may return favor & $25.8 \%$ & $21.3 \%$ \\
\hline
\end{tabular}

\section{Interpersonal Styles}

To measure interpersonal styles, participants were asked to select one choice from a 5-point frequency scale (never, rarely, sometimes, often, and always). Table 5 includes the frequency of responses for both studies of those who indicated often or always using each style.

Table 5. U.S. and Brazil Generation Z Student Interpersonal Styles

\begin{tabular}{lcc}
\hline Interpersonal Style & $\begin{array}{c}\text { U.S. Students } \\
\text { Often Always Use This } \\
\text { or Aly }(\boldsymbol{n}=\mathbf{7 5 4})\end{array}$ & $\begin{array}{c}\text { Brazil Students } \\
\text { Often or Always Use This } \\
\text { Style }(\boldsymbol{n}=\mathbf{1 , 4 8 1})\end{array}$ \\
\hline Doing & $91.1 \%$ & $79.9 \%$ \\
Thinking & $79.6 \%$ & $79.6 \%$ \\
Relating & $69.7 \%$ & $69.7 \%$ \\
Leading & $64.1 \%$ & $60.8 \%$ \\
\hline
\end{tabular}

\section{Learning Methods}

For learning methods, participants in both studies were asked to select a choice from a 3-point scale on the effectiveness of the particular method for their learning with $1=$ not effective, $2=$ somewhat effective, and $3=$ greatly effective. Table 7 includes the frequency of responses for those who indicated that the method was greatly effective for them. 
Table 7. U.S. and Brazil Learning Methods

\begin{tabular}{lcc}
\hline Learning Method & $\begin{array}{c}\text { U.S. Students } \\
(\boldsymbol{n}=\mathbf{7 0 4})\end{array}$ & $\begin{array}{c}\text { Brazil Students } \\
(\boldsymbol{n}=\mathbf{1 , 4 8 1})\end{array}$ \\
\hline Intrapersonal & $51.6 \%$ & $46.6 \%$ \\
Kinesthetic & $48.5 \%$ & $45.8 \%$ \\
Logical-mathematical & $43.1 \%$ & $41.6 \%$ \\
Musical & $42.7 \%$ & $31.3 \%$ \\
Linguistic & $42.1 \%$ & $53.7 \%$ \\
Spatial & $41.9 \%$ & $40.0 \%$ \\
Interpersonal & $36.3 \%$ & $39.2 \%$ \\
Naturalist & $26.1 \%$ & $27.8 \%$ \\
\hline
\end{tabular}

\section{Learning Styles}

To measure Learning Styles, participants in both studies were asked to select one choice from a 5point frequency scale similar to their responses for the Interpersonal Styles measurement. Table 6 includes the frequency of responses for those who indicated "often" or "always" using each style.

Table 6. U.S. and Brazil Generation Z Student Learning Styles

\begin{tabular}{lcc}
\hline Learning Style & U.S. Students $(\boldsymbol{n}=\mathbf{7 0 1})$ & Brazil Students $(\boldsymbol{n}=\mathbf{1 , 4 8 1})$ \\
\hline Logic & $83.7 \%$ & $75.5 \%$ \\
Experience & $80.3 \%$ & $59.8 \%$ \\
Practicality & $74.7 \%$ & $59.7 \%$ \\
Imagination & $55.6 \%$ & $56.7 \%$ \\
\hline
\end{tabular}

\section{Discussion and Implications}

The findings from both the U.S. and Brazil surveys note many similarities and some slight differences. The authors used these findings to derive several themes, which include learning that makes a difference, achievement orientation, logic-based learning, intrapersonal and interpersonal learning, applied and hands-on experiences, learning through words, recognition, lacking vision, inspiration, and creativity.

\section{Learning that Makes a Difference}

Both the U.S. and Brazil datasets indicate that $66 \%$ or more of Generation $\mathrm{Z}$ college students identify with the characteristics of being loyal and open-minded, which appear to be associated with making an impact on others. In addition, U.S. and Brazil students share four of the top five VIA character strengths, honesty, kindness, fairness, and judgment; all seemingly having a focus on positively interacting with or impacting others (VIA Institute on Character, 2018b). In looking specifically at motivations related to impacting others as well, making a difference for someone and advocating for something you believe in both yielded $66 \%$ or more for both the U.S. and Brazil groups. This is not surprising in that high numbers in the U.S. and Brazil groups characterize themselves as open-minded (nearly 70\% for the United States and 73\% for Brazil). Such findings align with those from the College Senior Survey in which Generation Z respondents rated themselves high on perspective-taking, tolerance, and cooperation with others from diverse backgrounds (Higher Education Research Institute, 2017). In addition, both groups had similar levels of openness from previous Big Five research (Schmitt et al., 2007). 
Although the desire to make an impact appears to resonate with both groups, it is a stronger theme for the U.S. students. Eighty percent of U.S. students identify as thoughtful and $73 \%$ as compassionate, whereas only $32 \%$ of those in Brazil identify as thoughtful and $55 \%$ as compassionate. In addition, one of the top three motivators for the U.S. students includes not wanting to let others down (75\%), which also reflects making an impact on others or with a cause. Not wanting to let others down, in particular, is $28 \%$ higher for U.S. students.

Despite the larger number of U.S. students who indicated a desire to make an impact, it was still a theme among Brazil students. Given that many in this generation in both countries self-identify and are motivated by factors related to making an impact, it might be important for educators to integrate social change learning, rather than service learning, into the curriculum. Finding ways for students to address underlying problems, versus symptomatic issues of a problem, can help mobilize their drive around wanting to make a sustainable difference for others. In addition, some students might ask, "How will I use this learning later in my life?"- but what about helping to answer the question, "How will this learning be able to help me make a difference for others?"

\section{Achievement Orientation}

More than two-thirds of both U.S. and Brazil Generation Z college students describe themselves as determined and responsible, both indicators of a desire for achievement. In addition, $67 \%$ of U.S. students and 53\% of Brazil students identify as driven. These findings align with Steele Flippin's (2017) study that found that those in Generation Z in the United States are eager, hardworking, and motivated and the Higher Education Research Institute's (2017) findings that U.S. Generation Z college students are driven to succeed. The slightly higher percentage of U.S. students than Brazil students who identify as being driven, in particular, may be reflective of the U.S. students' higher levels overall of conscientiousness in the Big Five study (Schmitt et al., 2007), as conscientiousness may involve behaviors related to goal setting and attainment.

But, it isn't just self-described characteristics that reflect the achievement orientation of the U.S. and Brazil students. Several achievement-oriented motivations were identified among $66 \%$ or more of the members of both groups. These motivations include wanting to do well because you took it on, opportunity for advancement, seeing fruits of labor, tangible rewards, and learning something. Although tangible rewards could be associated more with extrinsic motivation, many of the other prominent motivators of Generation $\mathrm{Z}$ for both groups appear to be more intrinsically focused.

While both the U.S. and Brazil student groups each identified unique achievement-oriented motivations specific to their groups, these motivations were similar. For example, (receiving) credit is $27 \%$ higher for U.S. students, while (gaining) experience is nearly $20 \%$ higher for Brazil students. Although different, both focus on working toward accumulating enough achievements to warrant a record of success, and both reflect extrinsic motivation.

When looking more closely at the top three motivators for each group, achievement appears to be more of a motivator for the Brazil students than the U.S. students. For the Brazil group, their top three motivators include seeing the fruits of labor (89\%), wanting to do well because you took it on (89\%), and opportunity for advancement (86\%), all motivations that focus on personal achievement. For the U.S. students, these numbers were lower at $68 \%$, nearly $67 \%$, and $74 \%$, respectively.

Although the U.S. students appear to have slightly higher frequencies of self-identifying as driven and a higher number of Brazil students appear to resonate with achievement-oriented motivations, personal achievement appears to be an important factor for Generation $\mathrm{Z}$ students in both countries. Given that, it may be important for educators to focus on creating small milestones for students to work towards so as to tap into their desire for achievement. For example, a large assignment could be divided into smaller parts so students could see their progress and feel a sense of accomplishment 
moving to the next task. In addition, there is an internal sense of achievement with both groups of students. They pride themselves on doing well on projects and tasks they take on and see if they can learn something from the process. Giving them opportunities to rewrite assignments after receiving feedback might be a strategic way to tap into their desire for continuous learning and doing good work.

\section{Logic-Based Learning}

In terms of learning styles, both groups prefer logic, followed by experience, practicality, and then imagination. While the numbers were somewhat higher for the United States (84\%) compared to Brazil (76\%), logic took the top spot for preference with both groups. This means that both groups enjoy engaging in learning when there are clear explanations and they are required to approach the work in an organized manner.

While it appears that both groups want their learning to be laid out in a logical manner, far fewer want to use logic or math to engage in learning ( $43 \%$ for the United States and $42 \%$ for Brazil).

Despite the heavy attention to increasing students' proficiency in science, technology, engineering, and mathematics in the United States that occurred in the early 2000s (Hallinen, 2017), it doesn't appear that a majority of students in either country prefer to learn using logic or math skills.

What might be telling from these findings is that Generation $\mathrm{Z}$ students in both countries want to have clear instructions and a logical and organized path to learning, likely so they feel confident in meeting expectations. Educators can support this by providing very specific and detailed explanations for both content as well as for instructions for assignments.

\section{Intrapersonal and Interpersonal Learning}

For the U.S. students, intrapersonal learning was the most selected learning style preference over every other option (52\%). For the Brazil students, it was the second most selected preference (47\%), after linguistic. Although similar, the U.S. students' higher rate may be consistent with another interesting finding related to characteristics. A far higher number of U.S. students identify as unique (62\%) and opportunistic (47\%) than their Brazil counterparts (49\% and $21 \%$, respectively). And, far more Brazil students (58\%) see themselves as collaborative than the U.S. students (38\%). These differences may be able to be explained by the cultural context of high individualism in the United States and low individualism in Brazil (Hofstede Insights, 2018) and may help in understanding the slight differentiation in each of these groups' desire for intrapersonal learning. In addition, both groups had lower numbers indicating a preference for interpersonal learning, with the United States at 36\% and Brazil slightly higher at 39\% despite their somewhat higher self-described characteristic of being collaborative.

Although many of them do not prefer interpersonal learning, both the U.S. and Brazil students have the same preferences for the roles they play. The first preference of both groups is doing, followed by thinking, relating, and then leading. While thinking and relating were nearly identical in response numbers, the United States had a much higher rate for doing at 91\% than Brazil at $80 \%$. It appears that both groups prefer doing more than other interpersonal styles and prefer leading the least. Their preference for doing might be explained in part by Rushmer's (1996) findings that completer finisher, which involves finalizing a task, is one of the most preferred Belbin team roles at least in the United States.

Overall, there appears to be a preference for both groups to engage in intrapersonal learning over interpersonal learning. It is not necessarily recommended to eliminate group work altogether 
as working with others can be helpful for students in developing critical interpersonal skills needed in the workplace (World Economic Forum, 2016). But, the desire for many of them for independent learning may lend itself to a scaffolded approach in which students have an opportunity to read about, reflect on, and apply learning by themselves before being asked to work in a group. This may help them clarify their thoughts, practice, and build confidence before being asked to demonstrate their learning in front of others.

\section{Applied and Hands-On Experiences}

The second most preferred learning style for both groups is experience. U.S. and Brazil students appear to have a propensity for hands-on learning where they can engage in technical activities over those that are more imaginative and creative, despite Steel-Flippin's (2017) findings that this generation is characterized as being creative.

For learning methods, there too were great similarities. Both U.S. and Brazil students indicated the kinesthetic learning method as their second-highest preference after intrapersonal. Despite their lack of preference for interpersonal learning, they want to be active learners in the classroom and not just passively consuming information. But, given the low rates of preference for naturalist learning for both the U.S. and Brazil students, they may prefer staying inside for their activities.

\section{Learning Through Words}

The most preferred learning method for Brazil students is linguistic at nearly $54 \%$, higher than the percentage of U.S. students, which is just around $42 \%$. This may be able to be explained by the slow integration of curriculum reform (National Curriculum Parameters) instituted in 1996 by the Brazil Ministry of Education (UNESCO, 2006). Although there were many aims to this reform, one goal was to move away from memorization and to learning through reasoning (UNESCO, 2006). However, by 2013, the reform was "slowly (and painfully) being accepted" (Miranda de Moraes, 2013, p. 101). This slow integration may have meant that some Brazil students in the study spent their younger schooling years experiencing pedagogical approaches focused on memorizing content, liken to the role of memory in linguistic learning.

Albeit not at incredibly high rates, more U.S. students appear to prefer musical learning than their Brazil counterparts (nearly $43 \%$ and $31 \%$, respectively). So, perhaps more U.S. students would like learning words if they were put to a tune.

\section{Recognition}

Just as important as it may be to learn what both groups do and do not have in common in terms of their highest preferences, it too can be informative to uncover the similarities and differences in their lowest preferences. For example, public recognition and individual recognition are not preferred forms of motivation by U.S. students, making both categories among the lowest in responses. However, while the Brazil students also do not appear to favor public recognition, more than double prefer individual recognition. It appears that neither group wants accolades in front of others; however, the Brazil students may see individual recognition as a result of their hard work and accomplishment, as influenced by their preference for achievement-oriented motivation. Thus, it might be important to avoid opportunities for public recognition with either student population, while keeping in mind that the students in Brazil appear to appreciate individual recognition. 


\section{Lacking Vision, Inspiration, and Creativity}

Both groups also share similarities with their lowest identifying characteristics, yielding under onethird of participants who indicated identifying as inspiring. And, just around one third of U.S. (36\%) and Brazil (33\%) students indicated seeing themselves as visionary.

As for Imagination as a learning style, its lowest spot on the preference list for both U.S. and Brazil students might not be that surprising. For instance, 45\% of U.S. Generation Z students in the 2017 College Senior Survey rated their creativity level as being average or below average (Higher Education Research Institute, 2017). Given that the World Economic Forum (2016) posited that creativity will be the third most essential career skill in 2020, having risen from the 10th spot in 2015, it will be critical to help Generation Z students in both countries develop their creativity.

\section{Limitations}

The main limitation for both surveys is the small sample size for each, making the findings interesting but not generalizable to a larger college population. In addition, percentage frequency was reported absent a margin of error. Thus, these findings may be more informative than statistically significant.

There are two main limitations in the comparative analysis. First, data collection was conducted at different times making global cultural context and even the disparity of ages different between the two populations studied. The U.S. data collection only included those born in 1995 and 1996, whereas the later data collection in Brazil included students born in 1995, 1996, 1997, 1998, and 1999. Second, both surveys were administered in the native language of each country, English for the United States and Portuguese for Brazil. This may have led to potential translation issues in the measurements from English to Portuguese with such long and descriptive questions and scales.

\section{Conclusion}

While both the United States and Brazil are quite different in their cultures, geography, history, and structures of their higher education institutions, there appear to be several similarities between Generation $\mathrm{Z}$ students in both countries. Perhaps the global nature of the world today in sharing similar technology, news, social media platforms, and entertainment along with the economic, political, and technological interdependence between both the United States and Brazil has created a larger cultural context in which young people in both nations are far more similar than different.

\section{References}

An, D., \& Carr, M. (2017). Learning styles theory fails to explain learning and achievement: Recommendations for alternative approaches. Personality and Individual Differences, 116, $410-416$.

Belbin. (2014). Method, reliability, validity, statistics and research: A comprehensive review of Belbin team roles. Retrieved from https://www.belbin.com/media/1158/belbin-uk-2014-acomprehensive-review.pdf

Belbin, R. M. (2000). Beyond the team. Abingdon, United Kingdom: Routledge.

Bixler, B. A. (n.d.). A multiple intelligences primer. Retrieved from http://www.personal.psu.edu/bxb11/MI/MultipleIntelligences_print.html

Brazil Ministry of Education. (2017). Higher education census: Statistical notes 2017. Retrieved from http://download.inep.gov.br/educacao_superior/censo_superior/documentos/2018/censo_da_ed ucacao_superior_2017-notas_estatisticas2.pdf 
Businessballs.com. (n.d.). Kolb learning styles. Retrieved from http://www.businessballs.com/kolblearningstyles.htm

Bye, D., Pushkar, D., \& Conway, M. (2007). Motivation, interest, and positive affect in traditional and nontraditional undergraduate students. Adult Education Quarterly, 57, 141-158.

Cerqueira, T. C. S. (2008). Estilos de aprendizagem de Kolb e sua importância na educação [Kolb's learning styles and its importance in education]. Journal of Learning Styles, 1, 109-123.

Chen, K., \& Jang, S. (2010). Motivation in online learning: Testing a model of self-determination theory. Computers in Human Behavior, 26, 741-752.

Cherry, K. (2018a). 6 Key ideas behind theories of motivation. Retrieved from https://www.verywellmind.com/theories-of-motivation-2795720

Cherry, K. (2018b). The big five personality traits: 5 major factors of personality. Retrieved from https://www.verywellmind.com/the-big-five-personality-dimensions-2795422

Chick, N. (2018). Learning styles. Retrieved from https://cft.vanderbilt.edu/guides-subpages/learning-styles-preferences/

Costa, P. T., McCrae, R. R., Zonderman, A. B., Barbano, H. E., Lebowitz, B., \& Larson, D. M. (1986). Cross-sectional studies of personality in a national sample: 2. Stability in neuroticism, extraversion, and openness. Psychology and Aging, 1, 144-149.

Fisher, S. G., Hunter, T. A., \& Macrosson, W. D. K. (2000). The distribution of Belbin team roles among U.K. managers. Personnel Review, 29, 124-140.

Gardner, H. (1993). Multiple intelligences: The theory in practice. New York, NY: Basic Books.

Graf, N. (2016). Today's young workers are more likely than ever to have a bachelor's degree. Retrieved from http://www.pewresearch.org/fact-tank/2017/05/16/todays-young-workers-aremore-likely-than-ever-to-have-a-bachelors-degree/

Gutierrez, D., Perri, K., \& Quackenbush, A. (2006). Exploring the multiple intelligences of community college students enrolled in online courses. Journal of College Teaching \& Learning, 3, 85-90.

Hallinen, J. (2017). STEM. Retrieved from https://www.britannica.com/topic/STEM-education

Healey, M., Kneale, P., \& Bradbeer, J. (2005). Learning styles among geography undergraduates: An international comparison. Area, 37, 30-42.

Higher Education Research Institute. (2017). College Senior Survey [Custom dataset]. Los Angeles, CA: Higher Education Research Institute.

Hofstede Insights. (2018). Country comparison. Retrieved from https://www.hofstedeinsights.com/country-comparison/brazil,the-usa/

International Encyclopedia of the Social Sciences. (2019). Achievement motivation. Retrieved from https://www.encyclopedia.com/social-sciences/applied-and-social-sciencesmagazines/achievement-motivation

Jaggars, S. S. (2014). Choosing between online and face-to-face courses: Community college student voices. American Journal of Distance Education, 28, 27-38.

Jaju, A., Hyokjin, K., \& Zinkhan, G. M. (2002). Learning styles of undergraduate business students: A cross-cultural comparison between the U.S., India, and Korea. Marketing Education Review, 12, 1-13.

Kayes. D. C. (2005). Internal validity and reliability of Kolb's Learning Style Inventory Version 3 (1999). Journal of Business and Psychology, 20, 249-257. 
Kichuk, S. L., \& Wiesner, W. H. (1997). The Big Five personality factors and team performance: Implications for selecting successful product design teams. Journal of Engineering and Technology Management, 14, 195-221.

Klein, P. D. (1997). Multiplying the problems of intelligence by eight: A critique of Gardner's theory. Canadian Journal of Education, 22, 377-394.

Knoema. (2018). U.S. population by age and generation. Retrieved from https://knoema.com/infographics/egyydzc/us-population-by-age-and-generation

Kolb, A. Y., \& Kolb, D. A. (2005a). Learning styles and learning spaces: Enhancing experiential learning in higher education. Academy of Management Learning and Education, 4, 193-212.

Kolb, A. Y., \& Kolb, D. A. (2005b). The Kolb learning style inventory-Version 3.12005 technical specifications. Retrieved from http://www.whitewaterrescue.com/support/pagepics/lsitechmanual.pdf

Learning and Skills Research Centre. (2004). Should we be using learning styles? What research has to say to practice. Retrieved from https://www.researchgate.net/publication/244441072_Should_We_Be_Using_Learning_Styles _What_Research_Has_to_Say_to_Practice

Lin, Y. G., \& McKeachie, W. J. (1999, August). College student intrinsic and/or extrinsic motivation and learning. Paper presented at the Annual Conference of the American Psychological Association, Boston, MA.

Lumsden, L. S. (1994). Student motivation to learn. ERIC Digest, 92, 4358.

Markus, H. R. (2016). What moves people to action? Culture and motivation. Current Opinion in Psychology, 8, 161-166.

McClelland, D. (2005). Achievement motivation theory. In J. B. Miner (Ed.), Organizational behavior I: Essential theories of motivation and leadership (pp. 46-60). New York, NY: M. E. Sharpe.

Miranda de Moraes, S. E. (2013). Curriculum tendencies in Brazil. In W. F. Pinar (Ed.), International handbook of curriculum research (2nd ed., pp. 101-111). New York, NY: Taylor and Francis.

National Student Clearinghouse Research Center. (2017). Current term enrollment estimates fall 2017. Retrieved from https://nscresearchcenter.org/current-term-enrollment-estimates-fall$2017 /$

Ross, M., Perkins, H., \& Bodey, K. (2016). Academic motivation and information literacy self-efficacy: The importance of a simple desire to know. Library \& Information Science Research, 38, 2-9.

Rushmer, R. K. (1996). Is Belbin's shaper really TMS's thruster-organizer? An empirical investigation into the correspondence between the Belbin and TMS team role models. Leadership \& Organization Development Journal, 17, 20-26.

Ryan, R. M., \& Deci, E. L. (2000). Self-determination theory and the facilitation of intrinsic motivation, social development, and well-being. American Psychologist, 55, 68-78.

Schloss, P., \& Cragg, K. (2013) Understanding the range of postsecondary institutions and programs. In P. Schloss \& K. Cragg (Eds.), Organization and administration in higher education (chapter 1). New York, NY: Routledge Press

Schmitt, D. P., Allik, J., McCrae, R. R., \& Benet-Martinez, V. (2007). The geographic distribution of Big Five personality traits: Patterns and profiles of human self-description across 56 nations. Journal of Cross-Cultural Psychology, 38, 173-212.

Seemiller, C. (2009). Motivation index. Unpublished manuscript, The University of Arizona, Tucson, Arizona. 
Steele Flippin, C. (2017). Generation $Z$ in the workplace. Author.

Tang, W., Cui, Y., \& Babenko, O. (2014). Internal consistency: Do we really know what it is and how to assess it? Journal of Psychology and Behavioral Science, 2, 205-220.

Terada, Y. (2018). Multiple intelligences theory: Widely used, yet misunderstood. Retrieved from https://www.edutopia.org/article/multiple-intelligences-theory-widely-used-yetmisunderstood

UNESCO. (2006). World data on education (6th ed.). Retrieved from https://www.oei.es/historico/pdfs/Brazil_datos2006.pdf

U.S. Department of Education. (2018). Digest of education statistics, 2016 (NCES 2017-094). Retrieved from https://nces.ed.gov/fastfacts/display.asp?id=84

VIA Institute on Character. (2018). The VIA Survey of Character Strengths: United States and Brazil Gen $Z$ [Custom dataset]. Cincinnati, OH: Author.

Westen, D., \& Rosenthal, R. (2003). Quantifying construct validity: Two simple measures. Journal of Personality and Social Psychology, 84, 608-618.

World Economic Forum. (2016). The future of jobs. Retrieved from http://reports.weforum.org/futureof-jobs-2016/

World Population Review. (2019). Total population by country 2019. Retrieved from http://worldpopulationreview.com/countries/

The Journal of Educational Research and Practice provides a forum for studies and dialogue that allows readers to better develop social change in the field of education and learning. Journal content may focus on educational issues of all ages and in all settings. It also presents peer-reviewed commentaries, book reviews, interviews of prominent individuals, and additional content. The objectives: We publish research and related content that examines current relevant educational issues and processes aimed at presenting readers with knowledge and showing how that knowledge can be used to impact social change in educational or learning environments. Additional content provides an opportunity for scholarly and professional dialogue regarding that content's usefulness in expanding the body of scholarly knowledge and increasing readers' effectiveness as educators. The journal also focuses on facilitating the activities of both researcher-practitioners and practitioner-researchers, providing optimal opportunities for interdisciplinary and collaborative thought through blogging and other communications. Walden University Publishing:

http://www.publishing.waldenu.edu 